\title{
Interfacial Structure of the Joints between Magnesium Alloy andmild Steel with Nickel as Interlayer
}

\author{
Guangxin. Zhang \\ College of Materials Science and Engineering \\ Shenyang Aerospace University \\ Shenyang,China \\ e-mail:xgzhang2419@163.com
}

Lu. Liu

College of Materials Science and Engineering

Shenyang Aerospace University

Shenyang,China

e-mail:11471460939@sohu.com

\author{
Chuang. Tian \\ College of Materials Science and Engineering \\ Shenyang Aerospace University \\ Shenyang,China \\ e-mail:18240085003@163.com \\ Rongzheng. $\mathrm{Xu}^{*}$ \\ College of Materials Science and Engineering \\ Shenyang Aerospace University \\ Shenyang, China \\ e-mail:rzxu@imr.ac.cn \\ *Corresponding author
}

\begin{abstract}
The joining of magnesium alloy AZ31B and mild steel Q235 is realized by the addition of a Ni interlayer using resistance spot welding technique. The bonding mechanisms of the dissimilar joining have been investigated using mechanical testing and metallurgical examination. The results show that the formation of intermetallic compound (Mg2Ni) and solid solution of $\mathrm{Ni}$ in $\mathrm{Fe}$ at the interface plays an important role in the bonding of $\mathrm{Mg}$ alloy and steel at the centre of the nugget zone, which contributes to the increase of the tensile shear strength of joints. Besides, $\mathrm{Mg}$ alloy and $\mathrm{Ni}$ interlayer are joined by $\mathrm{Mg} 2 \mathrm{Ni}$ intermetallic compound layer at the edge of the nugget zone, but steel and $\mathrm{Ni}$ interlayer only form a mechanical bonding.
\end{abstract}

\section{Keywords- Mg; Steel; Interlayer; Welding; Introduction}

\section{INTRODUCTION}

As is well known, steel is one of the dominant materials in industry and $\mathrm{Mg}$ is the lightest structural materials, therefore dissimilar welding of $\mathrm{Mg}$ alloys and steel is of great significance for the increased fuel economy and improved vehicle performance [1-4].Several studies are available in literature regarding the processes used to join $\mathrm{Mg}$ to $\mathrm{Fe}$, such as friction stir welding [5, 6], laser-tungsten-inert gas (TIG) hybrid welding [7, 8] and laser penetration brazing [9]. The problems encountered during dissimilar welding of $\mathrm{Mg}$ alloys and steel stem from the widely differing thermophysical properties (melting points, tensile strength), few solid solubility of $\mathrm{Mg}$ in $\mathrm{Fe}$ and the no tendency for intermetallic layer formation during the welding process. It is apparent from the binary $\mathrm{Mg} / \mathrm{Fe}$ equilibrium phase diagram that the solid solubility of $\mathrm{Mg}$ in $\mathrm{Fe}$ is 0.00043 at.\%, furthermore, there are not any types of intermetallic compounds between them. Therefore, resistance welding remains the principal joining process in the vehicle industry, but dissimilar joining between $\mathrm{Mg}$ alloy and steel using resistance spot welding (RSW) is problematic [10].

Liu et al. studied the joining of Mg alloy AZ31B and zinc-coated DP600 steel sheets using RSW. The result showed that $\mathrm{Zn}$ coating played an important role in facilitating the joining of $\mathrm{Mg}$ alloy to steel [10]. However, limited publications focused on the RSW of Mg to baresteel. In the previous studies, the addition of $\mathrm{Ni}$ interlayer was proved to be an effective method to enhance the shear strength of weld joint of $\mathrm{Mg}$ alloy to steel $[8,11]$. Ni can react with $\mathrm{Mg}$ and $\mathrm{Fe}$ in terms of their binary diagrams, thus metallurgical bonding between $\mathrm{Mg}$ alloy and Q235 mild steel may be realized, which may contribute to the improvement of strength of weld joints. Therefore, the RSW of Mg alloy and bare-steel may be potential by the addition of Ni interlayer.

In the present paper, the feasibility of joining of $\mathrm{Mg}$ alloy AZ31B and bare steel sheets with the addition of Ni interlayer using RSW is investigated. In addition, interfacial characterization of the joints between $\mathrm{Mg}$ alloy and steel with $\mathrm{Ni}$ as an interlayer is discussed.

\section{EXPERIMENTAL PROCEDURES}

\section{A. Materials and welding parameters}

The plate $(80 \times 12 \times 1.7 \mathrm{~mm})$ of AZ31 Mg alloy and the plate $(80 \times 12 \times 1.2 \mathrm{~mm})$ of Q235 steel were used for RSW with the compositions of Mg-3Al-1Zn-0.2Mn$0.1 \mathrm{Si}(\mathrm{wt} \%)$ and Fe-0.2C-0.3Si-0.7Mn (wt\%), respectively. The two plates were overlapped with the $\mathrm{Mg}$ alloy plate on top. The Ni interlayer with $99.9 \mathrm{wt} \%$ in purity and $0.1 \mathrm{~mm}$ in thickness was set between the two plates. Before welding, they were degreased and ground by acetone and 
abrasive papers. The specimens were welded using a median-frequency DC RSW machine. RSW process was carried out in an air atmosphere. The Flat-ended, round, $\mathrm{Cu}-1.0 \% \mathrm{Cr}$ electrodes of $8 \mathrm{~mm}$ diameter were used. In addition, the welding force and weld time were $1100 \mathrm{~N}$ and $0.4 \mathrm{~s}$, respectively.

\section{B. Analyzes of weld joint}

The samples used for microstructure analyses were abraded by $80^{\#}, 400^{\#}, 800^{\#}$ and $1000^{\#}$ grit emery papers and then polished by $1.0 \mu \mathrm{m}$ diamond paste. Afterwards, the samples were etched with nital or picric acid based etchant solution. Transverse cross-sections were analyzed by scanning electron microscope (SEM) with energy dispersive X-ray spectros-copy (EDS). The average value of strengths for at least 3 specimens was taken as the shear strength of the lap joint.

The weld joints were machined into the specimens for the shear testing. The tensile shear strength was calculated as follows:

$$
\sigma_{\text {b-shear }}=\frac{F}{S}
$$

where, $\mathrm{F}$ and $\sigma \mathrm{b}$ shea are the load and the ultimate shear strength, respectively. $\mathrm{S}$ is a rectangular bonding area of the joint before the shear testing, which could be evaluated according to the size of the fracture surface. The average value of strengths for at least 3 specimens was taken as the shear strength of the lap joint.

\section{RESULTS AND DISCUSSIONS}

\section{Macrostructure characterization of weld joint}

Fig. 1 shows the surface view of $\mathrm{Ni}$-added $\mathrm{Mg}$-steel weld joints. It is found that the Mg alloy and steel could be joined by RSW. Fig. 2 shows the cross-section macrograph of $\mathrm{Mg}$-steel joints. It can be seen that there are some pores in the nugget zone. In the RSW, the symmetric tip contours are used to weld $\mathrm{Mg}$ to steel, and then the heat generation and peak temperature at the steel side are much higher than those on the magnesium side (bulk resistance and thermal conductivity of magnesium are less than those of steel and $\mathrm{Ni}$ ), which could induce the melting of steel, evaporation of magnesium, and formation of pores in the nugget zone.

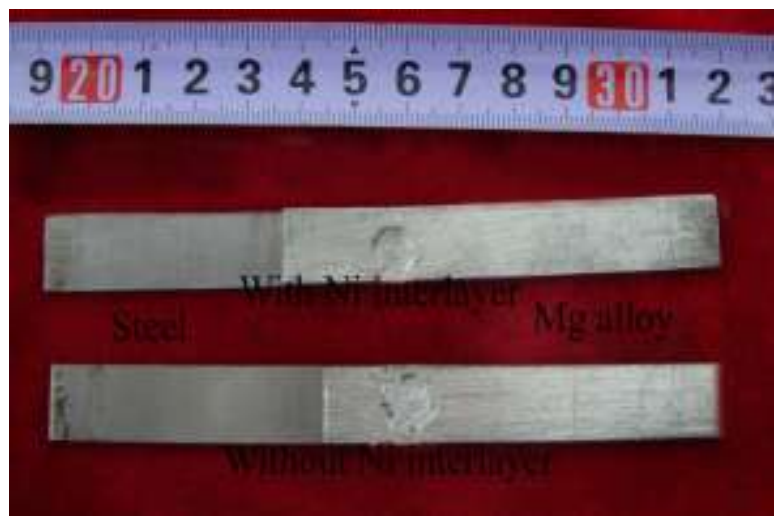

Figure 1. The surface view of $\mathrm{Ni}$-added $\mathrm{Mg}$-steel weld joints

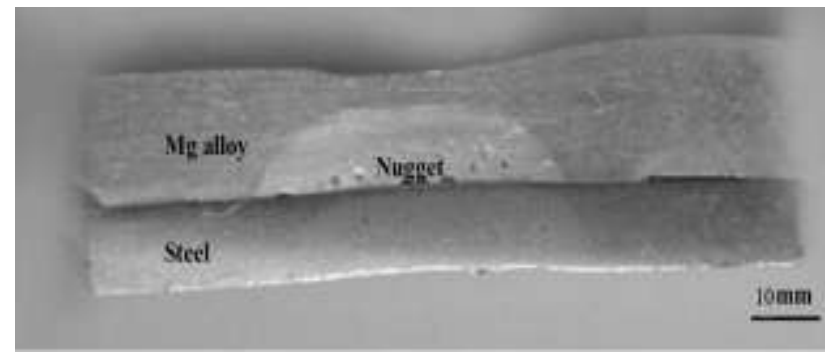

Figure 2. The cross-section macrograph of Mg-steel joints.

\section{Microstructure characterization of nugget zone}

Fig. 3 shows the microstructure characteristic of right side of a cross-sectioned joint. Two regions are defined according to the reaction content of $\mathrm{Ni}$ interlayer and substrate.

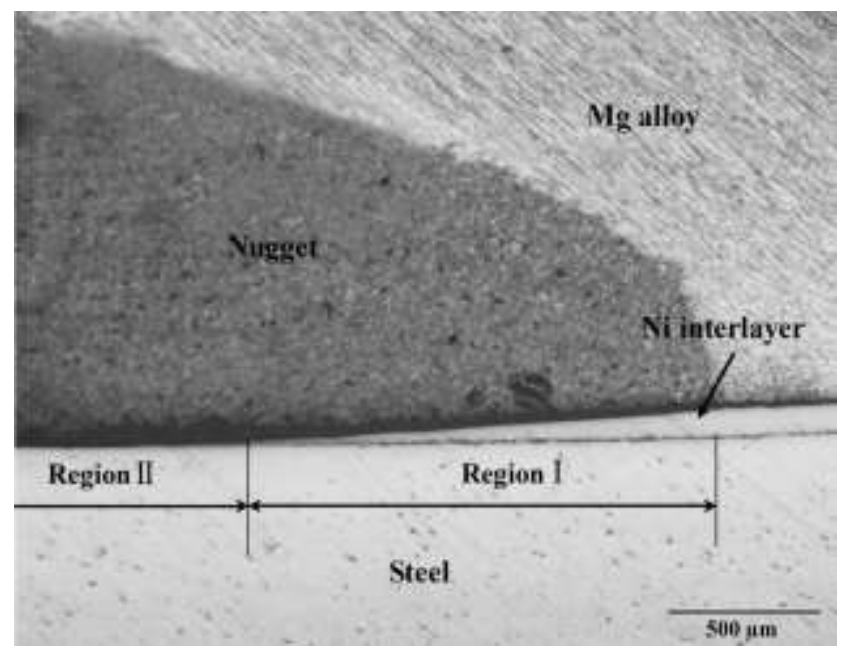

Figure 3. The microstructure characteristic of right side of a crosssectioned joint

Fig. 4 and 5 show the microstructure of $\mathrm{Mg}$-steel interface in Region I and II, respectively. In the Region $\mathrm{I}$, it is found that the melting of $\mathrm{Ni}$ is not sufficient because of the low temperature at the edge of nugget zone. Between $\mathrm{Mg}$ alloy and $\mathrm{Ni}$ interlayer, a new ribbon-shaped phase layer is generated indicting that $\mathrm{Mg}$ and $\mathrm{Ni}$ interlayer form a good metallurgical combination. However, Ni and steel almost could not form a connection in this zone. With increasing the temporary, the $\mathrm{Ni}$ interlayer almost disappears and begins to dissolve into the Mg substrate in the Region II . 


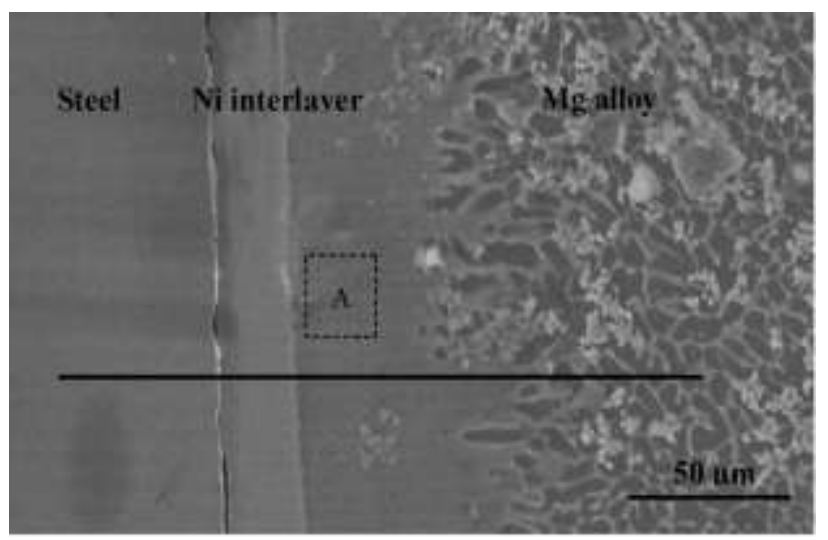

Figure 4. The microstructure of Mg-steel interface (Region I )

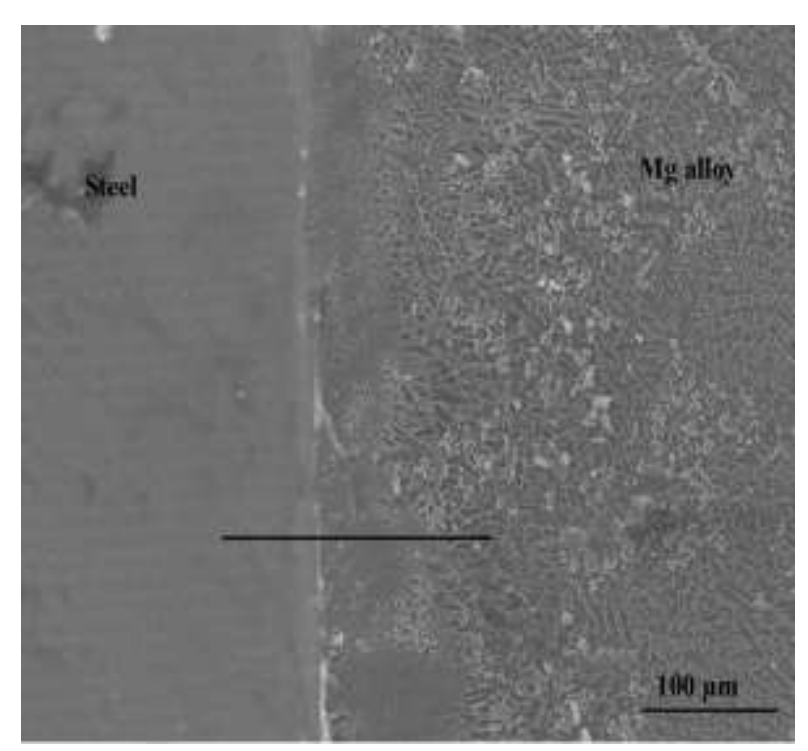

Figure 5. The microstructure of Mg-steel interface (Region II)

The new phase formed by the $\mathrm{Mg}$ and $\mathrm{Ni}$ interlayer improves the wettability of the $\mathrm{Mg}$ substrate on the steel surface and enhances the bonding strength of $\mathrm{Mg}$ alloy and steel. EDS results show that point A of Fig. 4 contains (wt) $40.1 \% \mathrm{Mg}$ and $59.9 \% \mathrm{Ni}$ implying that the IMC layer is composed of $\mathrm{Mg}_{2} \mathrm{Ni}$. However, for Ni-steel interface, little interdiffusion between $\mathrm{Ni}$ and steel is detected, which indicates that there are no reactions between them. According to the results of EDS and Fe-Ni binary phase diagram, the transitional layer is solid solution of $\mathrm{Ni}$ in $\mathrm{Fe}$ [12].

In the welding process, the steel and $\mathrm{Ni}$ interlayer at the interface could be melted at the same time and dissolved into each other, whereas the mixture of them could still be maintained without decomposition due to swift solidifying in the welding process. However, when the mixture of $\mathrm{Ni}$ and $\mathrm{Fe}$ is in liquid state, its temperature must be as high as $1400{ }^{\circ} \mathrm{C}$ at which $\mathrm{Mg}$ element must be in gaseous state. Therefore, there is no chance for $\mathrm{Mg}$ and $\mathrm{Ni}$ to be reacted at the same time, and thus no IMC layer is found in the TZ adjacent to the steel side. In the $\mathrm{TZ}$ adjacent to the $\mathrm{Mg}$ alloy side, there is obvious element diffusion of $\mathrm{Mg}$ and $\mathrm{Ni}$. In the welding process, the reaction of molten $\mathrm{Ni}$ and $\mathrm{Mg}$ is sufficient, consequently, a layer of intermetallic compound is generated in this zone. At the same time, some $\mathrm{Ni}$ elements dissolve into the nugget zone of $\mathrm{Mg}$ alloy side. The content of Ni element is much lower than that of $\mathrm{Mg}$ in the nugget zone, so the $\mathrm{Mg} 2 \mathrm{Ni}$ phases are formed and present discontinuous reticular shape in the nugget zone as shown in Fig. 6.

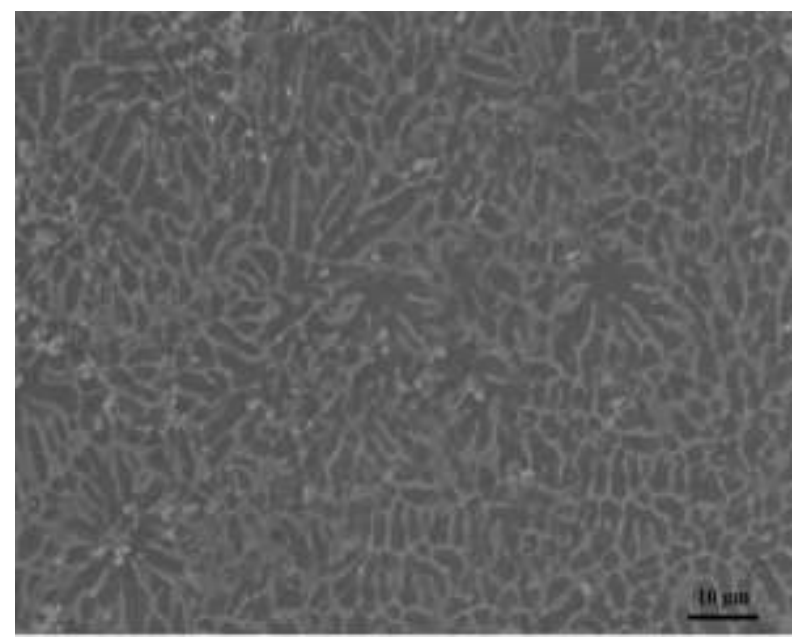

Figure 6. The microstructure of nugget zone on Mg alloy side

\section{A. Testing of tensile shear strength}

Fig. 7 shows the fracture location of Mg-steel joint. It can be seen that fracture usually occurs at such locations between interlayers and steel. The tensile shear test shows that the average shear strength of the joint is $75 \mathrm{MPa}$, which indicates that $\mathrm{Mg}$ and steel forms a good joining with the addition of $\mathrm{Ni}$ interlayer using RSW.

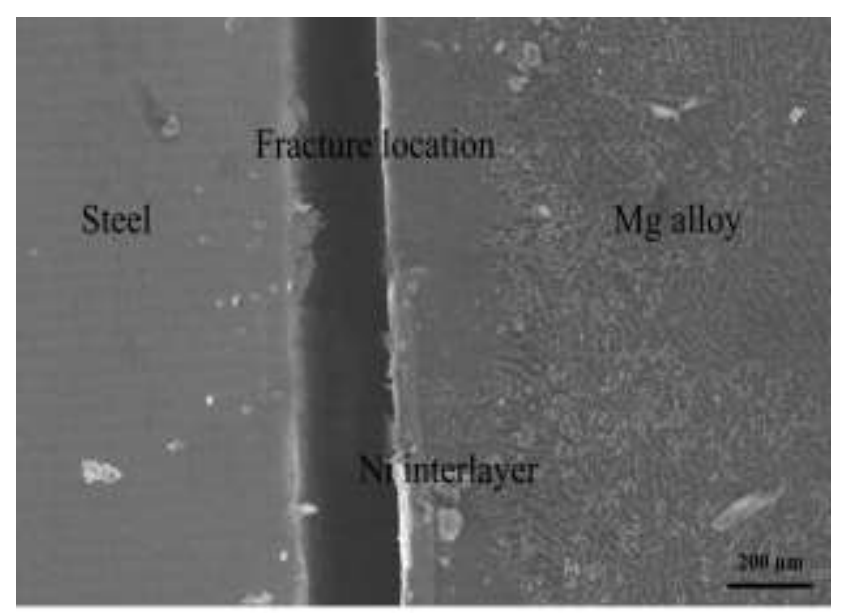

Figure 7. Fracture location of Mg-steel joint

\section{CONCLUSIONS}

AZ31B Mg alloy and Q235 steel are successfully joined using RSW technique. The shear strength of joint could 
reach $75 \mathrm{MPa}$. The addition of $\mathrm{Ni}$ interlayer plays an important role in enhancing the strength of $\mathrm{Mg}$-steel joints. The IMC layer $\mathrm{Mg} 2 \mathrm{Ni}$ is generated at the $\mathrm{Mg}-\mathrm{Ni}$ interface (Region I and II), and the solid solution of $\mathrm{Ni}$ in $\mathrm{Fe}$ is detected at the centre of the nugget (Region I ), but there is no metallurgical bonding between them at the edge of the nugget zone (Region I ).

\section{ACKNOWLEDGMENT}

The authors gratefully acknowledge the sponsorship from University Students' innovative training program (2012099), Liaoning Province Doctor Startup Fund Program Funded by Liaoning Province Education Administration (20131087) and Doctor Starting Foundation for Shenyang Aerospace University (12YB09).

\section{REFERENCES}

[1] T. Liyanage. J. Kilbourne, A. P. Gerlich. and T. H. North. oint formation in dissimilar $\mathrm{Al}$ alloy/steel and $\mathrm{Mg}$ alloy/steel friction stir spot welds $[\mathrm{J}]$. Science and Technology of Welding and Joining. vol. 14,2009 , pp.500-508.

[2] Elthalabawy W, Khan T. Microstructural development of diffusion-brazed austenitic stainless steel to magnesium alloy using a nickel interlayer [J]. Mater Charact. 2010, 61: pp. 703-712.

[3] Elthalabawy W, Khan T. Eutectic bonding of austenitic stainless steel 316L to magnesium alloy AZ31 using copper interlayer [J]. Int J Adv Manufact Technol. 2011, 55: pp. 235-241.
[4] Zhang HT, Feng JC, He P, Hackl H. Interfacial microstructure and mechanical properties of aluninmium-zinc-coated steel joints made by a modified metal inert gas welding-brazing process $[\mathrm{J}]$. Mater Charact. 2007, 58: pp. 588-592.

[5] T. Liyanage, J. Kilbourne and A. P. Gerlich: Joint formation in dissimilar $\mathrm{Al}$ alloy/steel and $\mathrm{Mg}$ alloy/steel friction stir spot welds [J]. Sci. Technol. Weld.Join.14, 2009, pp. 500-508.

[6] A. Scialpi, M. de Giorgi and L. A. C. de Filippise etal. Mechanical analysis of ultra-thin friction stir welding joined sheets with dissimilar and similar materials [J].Mater. Design, 2008, 29, pp. 928-936.

[7] Xiao-dong Qi. Li-ming Liu. Comparative study on characteristics of hybrid laser-TIG welded AZ61/Q235 lap joints with and without interlayers [J]. J Mater Sci (2010) 45: pp.3912-3920.

[8] Liu LM, Qi XD. Effects of copper addition on microstructure and strength of the hybrid laser-TIG welded joints between magnesium alloy and mild steel [J]. J Mater Sci 2009;44: pp.5725-31.

[9] Y. G. Miao, D. F. Han, J. Z. Yao and F. Li. Microstructure and interface characteristics of laser penetration brazed magnesium alloy and steel $[\mathrm{J}]$. Science and Technology of Welding and Joining. 15,2010, pp. $97-103$

[10] L. Liu, L. Xiao, J.C. Feng, Y.H. Tian, S.Q. Zhou, and Y. Zhou The mechanisms of resistance spot welding of magnesium to steel. Metallurgical and Materials transactions A [J]. 2010, 41A, pp.2651-2661.

[11] Qi XD, Song G. Interfacial structure of the joints between magnesium alloy and mild steel with nickel as interlayer by hybrid laser-TIG welding[J]. Mater Design.2010;31: pp.605-9.

[12] Kundu S, Chatterjee S. Interfacial microstructure and mechanical properties of diffusion-bonded titanium-stainless steel joints using a nickel interlayer[J]. Mater Sci Eng A 2006; 425: pp.107-13. 